\title{
Producción de amilasas de Geobacillus themoparaffinivorans (CB-13) aisladas de los Géiseres de Candarave, Tacna
}

\author{
Production of amylases from Geobacillus themoparaffinivorans (CB-13) isolated \\ from Candarave Geysers, Tacna
}

${ }^{1}$ Delsy Espinal Quiñonez

${ }^{2}$ Ariadna Zuñiga Llanos

\author{
${ }^{3}$ Daladier Castillo Cotrina \\ ${ }^{4}$ Roberto Castellanos Cabrera
}

\section{RESUMEN}

La investigación tuvo como objetivo determinar el diámetro del halo de hidrólisis amilolítico, la producción de proteínas amilásicas y la actividad enzimática de las amilasas producidas por Geobacillus thermoparaffinivorans (CB-13) a diferentes tiempos de producción. La cepa amilolítica de Geobacillus thermoparaffinivorans (CB-13), aislada de los géiseres de Candarave, Tacna se reactivó e incubó en caldo Luria Bertani (LB) a $60{ }^{\circ} \mathrm{C}$ durante 24 horas y se sembró por puntura en agar almidón $1 \%$ para determinar los halos de hidrólisis amilolíticos. Posteriormente, se inoculó $5 \%$ (v/v) de medio caldo LB con crecimiento bacteriano en $50 \mathrm{ml}$ de medio de caldo almidón $1 \%$ por triplicado, después fue incubado en estufa con agitador orbital a $150 \mathrm{rpm}$ a $60^{\circ} \mathrm{C}$ durante 60 horas. Asimismo, se extrajeron de cada incubación, con periodos de tiempo de 12 horas, alícuotas de $1.5 \mathrm{ml}$ para ser centrifugadas y obtener el sobrenadante que se utilizó para determinar la concentración de proteínas $\left(\mathrm{mg} \mathrm{ml}^{-1}\right)$ como indicativo de la producción de amilasas, y la concentración de azúcares reductores como indicativo de la actividad enzimática $\left(\mathrm{U} \mathrm{ml}^{-1}\right)$. Se obtuvo un diámetro de halo de hidrólisis de almidón formado alrededor de la colonia de la cepa amilolítica de $10.6 \mathrm{~mm}$, una producción de amilasas máxima de $0.197 \mathrm{mg} \mathrm{ml}^{-1}$ a las 48 horas de producción y una actividad enzimática máxima a las 36 horas de producción de $0.505 \mathrm{U} \mathrm{ml}^{-1}$.

Palabras claves: Actividad enzimática, Geobacillus thermoparaffinivorans (CB-13), producción de amilasas.

\section{ABSTRACT}

The objective of this study was to determine the diameter of the amylolitic hydrolysis halo, the amylasic protein production and the enzymatic activity of the amylases produced by Geobacillus thermoparaffinivorans (CB-13) are determined at different production times of the amylases. The amilolytic strain of Geobacillus thermoparaffinivorans (CB-13) isolated from the Candarave geysers was reactivated and incubated in Luria Bertani (LB) broth at $60^{\circ} \mathrm{C}$ for 24 hours and planted by puncturing on $1 \%$ starch agar to determine the amylolitic hydrolysis halos. Subsequently, $5 \%$ (v/v) of LB medium broth with bacterial growth in $50 \mathrm{ml}$ of $1 \%$ starch broth medium, in triplicate. Then, it was incubated in an orbital shaker at $150 \mathrm{rpm}$ at $60^{\circ} \mathrm{C}$ for 60 hours. Likewise, aliquots of $1.5 \mathrm{ml}$ were extracted from each incubator with 12 hour period, to be centrifuged to obtain the supernatant, which was used to determine the concentration of proteins ( $\mathrm{mg} \mathrm{ml}-1)$ as indicative of the production of amylases and the concentration of reducing sugars as indicative of the enzymatic activity (U ml-1). It was obtained a diameter of hydrolysis halo of starch formed around the colony of the $10.6 \mathrm{~mm}$ amylolitic strain, a maximum amylase production of $0.197 \mathrm{mg} \mathrm{ml}-1$ after 48 hours of production, and a maximum enzymatic activity after 36 hours of production of $0.505 \mathrm{U} \mathrm{ml-1}$.

Key words: Production of amylases, enzymatic activity, Geobacillus thermoparaffinivorans (CB-13)

\footnotetext{
Laboratorio de Investigación Biotecnología Enzimática. Facultad de Ciencias. Universidad Nacional Jorge Basadre Grohmann, Tacna, Perú. E-mail: delsymirian@gmail.com

Laboratorio de Investigación Biotecnología Enzimática. Facultad de Ciencias. Universidad Nacional Jorge Basadre Grohmann, Tacna, Perú. E-mail: ariadnazunigallanos@gmail.com

${ }^{3}$ Facultad de Ciencias. Universidad Nacional Jorge Basadre Grohmann, Tacna, Perú. Email: daladiercastillo@hotmail.com

${ }^{4}$ Laboratorio de Investigación Biotecnología Enzimática. Facultad de Ciencias. Universidad Nacional Jorge Basadre Grohmann, Tacna, Perú. E-mail: robertocastellanos@yahoo.es
} 


\section{INTRODUCCIÓN}

Las amilasas son enzimas que hidrolizan las moléculas de almidón para dar productos que incluyen las dextrinas y unidades de glucosa (Windish y Mhatre, 1965; Guano, 2017; Robledo, 2018). Tienen aplicaciones en las industrias de comida, fermentación, textil y papelería (Gupta, Paresh, Mohapatra, Goswami \& Chauhan, 2003; Robledo, 2018; Aguirre y Anduezal, 2018). Derivan de varias fuentes incluyendo plantas, animales y microorganismos; siendo las de origen microbiano las que por lo general cumplen con las demandas industriales. Un gran número de amilasas microbianas son una variable comercial, sustituyendo casi por completo la hidrólisis química del almidón en la industria de procesamiento del almidón (Pandey, Nigam, Soccol, Soccol, Singh \& Mohan, 2000).

Los microorganismos productores de amilasas son numerosos; entre ellos están Bacillus licheniformis, Bacillus stearothermophilus y Bacillus amyloliquefaciens, muy conocidos por ser buenos productores de la enzima. Estos se han usado ampliamente para la producción comercial $\mathrm{y}$ en diversas aplicaciones industriales como en los alimentos, la fermentación, los textiles y el papel (Konsula y Kyriakides, 2007; Prakash y Jaiswal, 2009).

La termoestabilidad es una característica deseada de la mayoría de las enzimas industriales. Estas enzimas termoestables aisladas de organismos termófilos tienen un número de aplicaciones comerciales a causa de su estabilidad a altas temperaturas, lo que permite que sean empleadas en la licuefacción enzimática y sacarificación del almidón. Las enzimas amilolíticas termoestables se han investigado actualmente para mejorar los procesos industriales de la degradación del almidón (Gomes et al., 2003; Stamford Stamford, Coelho \& Araujo, 2001).

Geobacillus thermoparaffinivorans es una bacteria termófila productora de amilasas, termoestable (Gursahani, 2010). Una de sus cepas, la CB-13, presente en el laboratorio de Biotecnología enzimática de la Facultad de Ciencias de la Universidad Nacional Jorge Basadre Grohmann de Tacna-Perú y aislada de los géiseres de Candarave-Tacna, es una bacteria que aún no ha sido estudiada, por lo cual en este trabajo se estudió algunas características.

Establecer la producción de amilasas en términos de producción de proteínas y su actividad enzimática en función de diámetros de halos de hidrólisis y/o de unidades de actividad por ml, nos permitirá predecir el grado de hidrólisis del almidón, considerando que las amilasas son proteínas que actúan sobre el almidón (Windish y Mhatre, 1965; Pandey et al., 2000).

El presente trabajo se orientó en determinar el diámetro del halo de hidrólisis amilolítico, la producción y actividad enzimática de amilasas p roducidas por Geobacillus thermoparaffinivorans (CB-13) a diferentes tiempos de producción de amilasas, reportadas por primera vez.

\section{MATERIAL Y MÉTODOS}

\section{Procedencia y reactivación de la cepa Geobacillus thermoparaffinivorans (CB-13)}

La cepa bacteriana amilolítica Geobacillus thermoparaffinivorans (CB-13) fue aislada de los Géiseres de Calientes-Candarave, Tacna, Perú, identificada molecularmente y proporcionada por el Laboratorio de Investigación Biotecnología Enzimática de la Facultad de Ciencias de la Universidad Nacional Jorge Basadre Grohmann de Tacna, y replicada en agar nutritivo contenido en un tubo de ensayo, luego reactivado por triplicado en un $\mathrm{ml}$ de caldo Luria Bertani (LB) (peptona $10 \mathrm{gl}^{-1}$, extracto de levadura $5 \mathrm{gl}^{-1}$, cloruro de sodio $10 \mathrm{gl}^{-1}$ ) e incubada a $60^{\circ} \mathrm{C}$ por 24 horas.

\section{Determinación del halo amilolítico de la cepa Geobacillus thermoparaffinivorans (CB-13)}

Reactivada la cepa en caldo LB, se le extrajo un inóculo que se sembró por puntura en el medio Agar A(a)lmidón (peptona $0.5 \%$, extracto de levadura $0.2 \%$, cloruro de sodio $0.05 \%$, sulfato de magnesio $0.05 \%$, cloruro de calcio $0.015 \%$, almidón $1 \%$, agar 2\%) (Souza y Leal, 2000) contenido en placas Petri e incubado a $60^{\circ} \mathrm{C}$ por 24 horas. Al final de esta incubación, se reveló la zona de hidrólisis por amilasas alrededor de las colonias desarrolladas, cubriendo con lugol al 30 $\%$ por 5 minutos la superficie del medio contenida en la placa Petri, para finalmente retirar el lugol. Fue medido el diámetro del halo con ayuda de una regla milimetrada.

\section{Obtención de fermentaciones para determinación de proteínas y actividad enzimática de amilasas}

Todo el ml de medio caldo LB con la cepa reactivada se sembró en $4 \mathrm{ml}$ de caldo LB nuevo, 
por triplicado, y se incubó a $60{ }^{\circ} \mathrm{C}$ hasta obtener una densidad óptica (D.O.) de 0.3 en el espectrofotómetro a una longitud de onda de 600 $\mathrm{nm}$

Se inoculó $5 \%(\mathrm{v} / \mathrm{v})$ de medio caldo $\mathrm{LB}$ con crecimiento bacteriano en $50 \mathrm{ml}$ de medio de caldo almidón (peptona $5 \mathrm{gl}^{-1}$, extracto de levadura $5 \mathrm{gl}^{-1}$, almidón $10 \mathrm{gl}^{-1}, \mathrm{NaCl} 1 \mathrm{gl}^{-1}, \mathrm{KH}_{2} \mathrm{PO}_{4} 0.5 \mathrm{gl}^{-1}$, $\mathrm{MgSO}_{4} 0.5 \mathrm{gl}^{-1}, \mathrm{CaCl}_{2} 0.5 \mathrm{gl}^{-1}, \mathrm{~K}_{2} \mathrm{HPO}_{4} 1.2 \mathrm{gl}^{-1}$ ) (Manoj, 2013) a pH 7 contenido en matraces de $250 \mathrm{ml}$ por triplicado. Se incubaron los matraces en una estufa incubadora con agitador orbital (shaker mrc) a $150 \mathrm{rpm}$ a $60^{\circ} \mathrm{C}$ durante 60 horas. Extrayendo de cada matraz, desde la cero horas y cada 12 horas (Annamalai, Thavasi, Vijayalakshmi \& Balasubramanian, 2011), alícuotas de $1.5 \mathrm{ml}$ para ser centrifugadas a 10000 rpm durante 10 minutos, para obtener dos fracciones a) el sedimento, que fue descartado y b) el sobrenadante, que sirvió para determinar la concentración de proteínas $\left(\mathrm{mg} \mathrm{ml}^{-1}\right)$ como indicativo de la producción de amilasas y la concentración de azúcares reductores como indicativo de la actividad enzimática de las amilasas $\left(\mathrm{U} \mathrm{ml}^{-1}\right)$.

\section{Cuantificación de la producción de amilasas}

Se realizó por el método descrito por Bradford (1976), para lo cual se estableció una curva estándar de proteínas BSA (Albúmina Suero Bovina). Para establecer esta curva, se tomó como muestra $50 \mu \mathrm{l}$ de solución de proteínas BSA a diferentes concentraciones, para que cada una de ellas se mezclara con $500 \mu \mathrm{l}$ del reactivo de Bradford, dejándolo actuar por un minuto. Para el blanco del reactivo se usó la misma proporción y cantidad reemplazando la muestra con agua destilada. Finalmente se midió en el espectrofotómetro la absorbancia a $595 \mathrm{~nm}$.

En los tratamientos experimentales (sobrenadante de los matraces de las $0,12,24,36,48$ y 60 horas), la medición de la producción de amilasas (proteínas) se realizó siguiendo el procedimiento descrito por Bradford (1976), que consistió en mezclar la muestra (sobrenadante) con el reactivo Bradford, dejándolo actuar durante 1 minuto. Para, finalmente, medir en el espectrofotómetro la absorbancia, la cual al ser llevada a la curva patrón permitió la determinación de la concentración de proteínas (amilasas) $\left(\mathrm{mg} \mathrm{ml}^{-1}\right)$.

\section{Cuantificación de la actividad enzimática de las amilasas}

Se midió la actividad enzimática amilolítica, estableciendo previamente la curva estándar de concentraciones de soluciones de glucosa $\left(\mathrm{mg} \mathrm{ml}^{-1}\right)$. Para obtener esta curva se mezcló todos los tubos conteniendo solución de glucosa estándar de diferentes concentraciones para luego ser llevados al espectrofotómetro y leer las absorbancias a una longitud de onda de $540 \mathrm{~nm}$. Los valores de absorbancia obtenidos se graficaron con la concentración de glucosa que sirvió después para determinar la concentración de glucosa de los tratamientos experimentales.

En los tratamientos experimentales (sobrenadante de los matraces de las $0,12,24,36,48$ y 60 horas), la medición de la actividad enzimática de amilasas se realizó determinando previamente la concentración de glucosa, para lo cual se empleó el método de ácido 3.5 dinitrosalisílico (DNS).

Tabla 1. Procedimiento para medir la concentración de glucosa producto de la actividad enzimática de las amilasas

\begin{tabular}{|c|c|c|c|c|}
\hline Reactivos & BR & BS & BE & ES \\
\hline Buffer fosfato de sodio pH 7 a $50 \mathrm{mM}(\mu \mathrm{l})$ & 150 & 50 & 100 & 0 \\
\hline Dilución de enzima $(\mu 1)$ & 0 & 0 & 50 & 50 \\
\hline Sustrato almidón $1 \%(\mu l)$ & 0 & 100 & 0 & 100 \\
\hline \multicolumn{5}{|c|}{ Incubar los tubos ependorf a $60^{\circ} \mathrm{C}$ por 30 minutos } \\
\hline Reactivo DNS $(\mu 1)$ & 250 & 250 & 250 & 250 \\
\hline \multicolumn{5}{|c|}{ Colocar los tubos en el baño de agua hirviendo durante 5 minutos e innmediatamente enfriarlos en baño de agua } \\
\hline Agua destilada $(\mu \mathrm{l})$ & 500 & 500 & 500 & 500 \\
\hline \multicolumn{5}{|c|}{ Agitar bien los tubos y leer las absorbancias a $540 \mathrm{~nm}$ contra el blanco de reactivo BR } \\
\hline \multicolumn{5}{|c|}{$\begin{array}{l}\text { Finalmente hacer corresponder las absorbancias obtenidas con las de la curva } \\
\text { patrón para establecer la concentración de glucosa producida }\end{array}$} \\
\hline \multicolumn{5}{|c|}{$\begin{array}{l}\text { * BR: tubo blanco del reactivo } \\
\text { BS: tubo blanco del sustrato } \\
\text { BE: tubo blanco de la enzima } \\
\text { ES: tubo con enzima sustrato }\end{array}$} \\
\hline
\end{tabular}

Fuente: Gutierrez y Villena, 2010. 
Luego, la actividad enzimática de amilasas se calculó mediante la siguiente expresión:

$$
\text { Amilasa }\left(\mathrm{U} \mathrm{ml}^{-1}\right)=[\mathrm{Glu}] \times 0.37 \times \text { dilución }
$$

Dónde: 0.37 es un factor para obtener el número de $\mu$ moles de glucosa formados en un minuto.

$\mathrm{La}$ actividad de amilasas fue expresada en $\mathrm{U} \mathrm{ml}^{-1}$, donde una unidad de enzima (U) se define como la cantidad de enzima que libera $1 \mu \mathrm{mol}$ de glucosa por minuto(Miller, 1959).

\section{RESULTADOS}

\section{Halo amilolítico originado por la cepa Geobacillus thermoparaffinivorans (CB-13)}

La actividad amilolítica de Geobacillus thermoparaffinivorans (CB-13) se muestra a través de los halos de hidrólisis de almidón formados alrededor de sus colonias, cuyo diámetro en promedio fue $10.6 \mathrm{~mm}$ que resultó de promediar el diámetro de 4 colonias $(10.0,10.0$, 11.0 y $11.5 \mathrm{~mm}$ ) (Figura 1 ).

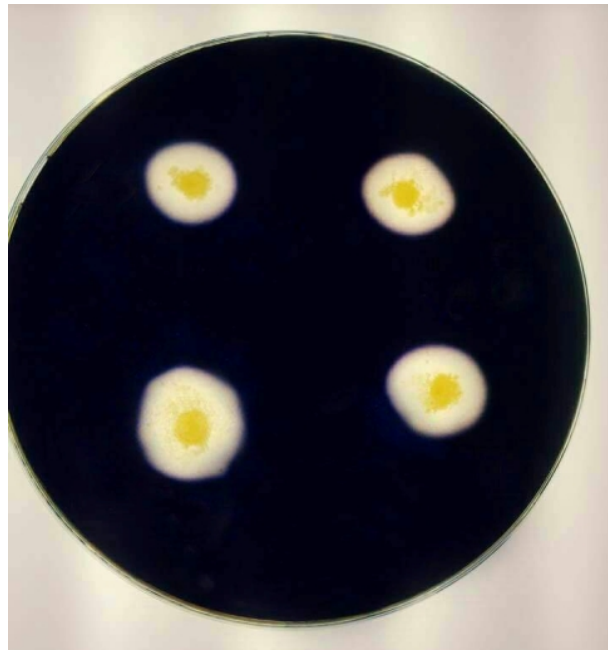

Figura 1. Halos amilolíticos alrededor de las colonias de Geobacillus thermoparaffinivorans (CB-13).

\section{Concentraciones de proteínas amilolíticas de Geobacillus thermoparaffinivorans (CB-13)}

En la Tabla 1, entre los valores promedio de producción de proteínas amilolíticas de Geobacillus thermoparaffinivorans (CB-13), obtenidas a diferentes tiempos de producción, se muestra que a las 48 horas de producción se obtiene el mayor valor de concentración de proteínas $0.197 \mathrm{mg} \mathrm{ml}^{-1}$.
Tabla 1. Valores promedio de producción de proteinas amilolíticas de Geobacillus thermoparaffinivorans (CB-13) a diferentes tiempos de producción

\begin{tabular}{|c|c|c|c|}
\hline $\begin{array}{l}\text { Tiempo } \\
\text { (horas) }\end{array}$ & Repeticiones & $\begin{array}{l}\text { Producción de } \\
\text { proteínas } \\
\left(\mathrm{mg} \mathrm{ml}^{-1}\right)\end{array}$ & Promedio \\
\hline \multirow{3}{*}{$\mathbf{0}$} & I & 0.094 & 0.095 \\
\hline & II & 0.083 & \\
\hline & III & 0.107 & \\
\hline \multirow{3}{*}{12} & I & 0.113 & 0.115 \\
\hline & II & 0.117 & \\
\hline & III & 0.116 & \\
\hline \multirow{3}{*}{24} & I & 0.121 & 0.128 \\
\hline & II & 0.129 & \\
\hline & III & 0.134 & \\
\hline \multirow{3}{*}{36} & I & 0.193 & 0.195 \\
\hline & II & 0.203 & \\
\hline & III & 0.188 & \\
\hline \multirow{3}{*}{48} & I & 0.192 & 0.197 \\
\hline & II & 0.217 & \\
\hline & III & 0.182 & \\
\hline \multirow{3}{*}{60} & I & 0.170 & 0.168 \\
\hline & II & 0.166 & \\
\hline & III & 0.168 & \\
\hline
\end{tabular}

Medias y 95,0\% de Fisher LSD

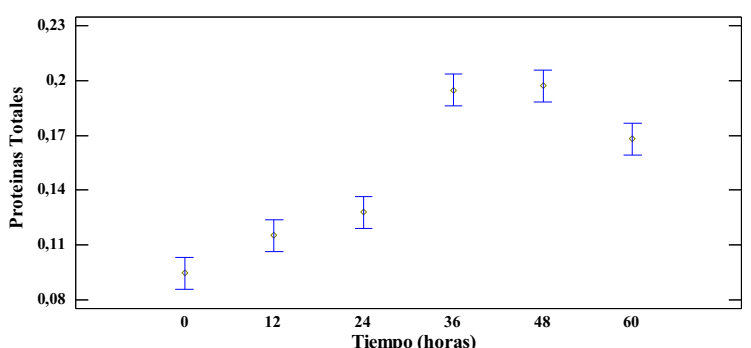

Figura 2. Valores promedio de producción de proteínas amilolíticas de Geobacillus thermoparaffinivorans (CB-13) a diferentes tiempos de producción en forma gráfica.

Fuente: Statgraphics centurión XVI

El análisis de varianza aplicado a los valores promedio de proteínas de la Tabla 1 da un resultado que, al ser el valor-P de la prueba $\mathrm{F}$ menor que 0.05 , indica que existe una diferencia estadísticamente significativa entre las medias de los valores promedios de producción de proteínas 
con un nivel del $95.0 \%$ de confianza; es decir que el tiempo afecta considerablemente la producción de proteínas amilolíticas. Por la prueba de Tukey se demuestra que la mayor producción de proteínas amilolíticas fue a las 48 horas de producción con el valor de $0.197 \mathrm{mg} \mathrm{ml}^{-1}$ (Tabla 1) (Figura 2).

\section{Actividad enzimática amilolítica de Geobacillus thermoparaffinivorans (CB-13)}

En la Tabla 2, entre los valores promedio de actividad amilolítica de las amilasas de Geobacillus thermoparaffinivorans (CB-13), obtenidas a diferentes tiempos de producción de amilasas, se muestra que a las 36 horas de producción se obtiene el mayor valor de actividad enzimática $\left(0.505 \mathrm{U} \mathrm{ml}^{-1}\right)$.

Tabla 2. Valores promedio de actividad amilolitica de las amilasas de Geobacillus thermoparaffinivorans (CB-13) a diferentes tiempos de producción de las amilasas

\begin{tabular}{|c|c|c|c|}
\hline $\begin{array}{l}\text { Tiempo } \\
\text { (horas) }\end{array}$ & Repeticiones & $\begin{array}{l}\text { Actividad } \\
\text { en } \mathrm{U} \mathrm{ml}^{-1}\end{array}$ & $\begin{array}{c}\text { Promedio } \\
\mathrm{U} \mathrm{ml}^{-1}\end{array}$ \\
\hline \multirow{3}{*}{$\mathbf{0}$} & I & 0.028 & 0.027 \\
\hline & II & 0.026 & \\
\hline & III & 0.029 & \\
\hline \multirow{3}{*}{12} & I & 0.065 & 0.070 \\
\hline & II & 0.074 & \\
\hline & III & 0.072 & \\
\hline \multirow{3}{*}{24} & I & 0.154 & 0.158 \\
\hline & II & 0.161 & \\
\hline & III & 0.158 & \\
\hline \multirow{3}{*}{36} & I & 0.511 & 0.505 \\
\hline & II & 0.565 & \\
\hline & III & 0.438 & \\
\hline \multirow{3}{*}{48} & I & 0.351 & 0.349 \\
\hline & II & 0.333 & \\
\hline & III & 0.362 & \\
\hline \multirow{3}{*}{60} & I & 0.122 & 0.122 \\
\hline & II & 0.128 & \\
\hline & III & 0.116 & \\
\hline
\end{tabular}

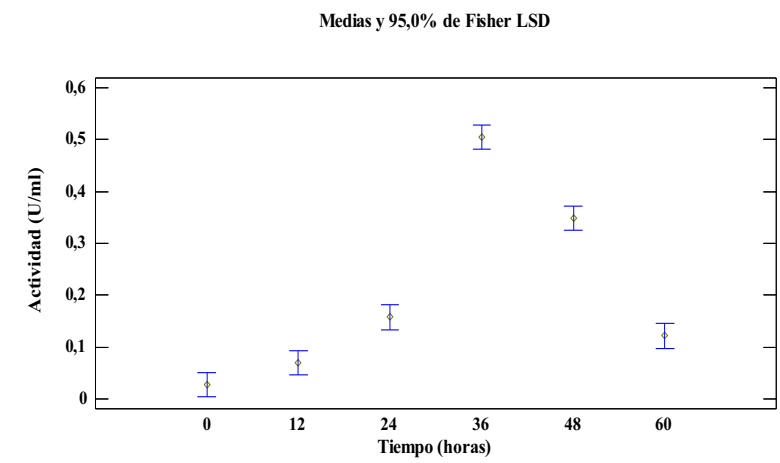

Figura 3. Valores promedio de actividad amilolítica de las amilasas de Geobacillus thermoparaffinivorans (CB-13) a diferentes tiempos de producción de las amilasas en forma gráfica.

Fuente: Statgraphics centurión XVI

El análisis de varianza, aplicado a los valores de actividad enzimática de la Tabla 2, da como resultado que al ser el valor-P de la prueba $\mathrm{F}$ menor que 0.05 , indica que existe una diferencia estadísticamente significativa entre las medias de las actividades enzimáticas $\left(\mathrm{U} \mathrm{ml}^{-1}\right)$ con un nivel del $95.0 \%$ de confianza; es decir, que el tiempo de producción afecta considerablemente la actividad enzimática. Por la prueba de Tukey se demuestra que la mayor actividad enzimática de las amilasas fue a las 36 horas de producción con el valor de $0.505 \mathrm{U} \mathrm{ml}^{-1}$ (Tabla 2) (Figura 3).

\section{DISCUSIÓN}

Los halos de hidrólisis de almidón, la producción de amilasas y la determinación de la actividad amilolítica puede variar en sus valoraciones. El valor que se obtenga depende principalmente del medio de nutriente, $\mathrm{pH}$, temperatura y el tiempo de incubación (Figen, Bilal, Seda \& Tulin, 2006). En este trabajo es evidente que la máxima producción de amilasas, así como el máximo valor de actividad enzimática, dependen mucho del tiempo de incubación; en este caso, estos fueron alcanzados cerca a las 60 horas de incubación de producción de proteínas amilolíticas, manteniendo constante los otros parámetros de concentración de almidón al $1 \%$, $\mathrm{pH}$ del medio igual a 7, temperatura de incubación $60{ }^{\circ} \mathrm{C}$ y agitación constante. 
El halo de hidrólisis de almidón de la cepa microbiana, aspecto cualitativo de la actividad enzimática amilolítica, con un diámetro de 10.6 $\mathrm{mm}$ da el indicativo que la actividad enzimática de Geobacillus thermoparaffinivorans (CB-13) es significativo. Este valor supera al diámetro de halos de hidrólisis de almidón encontrados en otros microorganismos, Levadura AAA 6 (10 $\mathrm{mm}$ ), Bacillus spp. (9 mm) (Gómez, Sarmiento y Delgado, 2013).

El aspecto cuantitativo determinado en la actividad enzimática en su valor máximo, $0.505 \mathrm{U}$ $\mathrm{ml}^{-1}$, para Geobacillus thermoparaffinivorans (CB-13) indica que las amilasas producidas por esta cepa tienen excelentes propiedades hidrolíticas. Las actividades enzimáticas de estas amilasas no están lejos de otras amilasas, siendo en la mayoría de los casos la actividad enzimática muy superior. Unal (2015), quien trabajó con especies de Aspergillus, logró obtener al sétimo día de producción $0.75 \mathrm{U} \mathrm{ml}^{-1}$ de actividad enzimática para Aspergillus terreus. Kumar, Raut, Satpathy, Ranjan \& Bandvopadhyay (2014), quienes trabajaron con bacterias termófilas productoras de amilasa, $B$. barbaricus durante 24 horas, obtuvieron una actividad máxima de amilasa de $0.574 \mathrm{U} \mathrm{ml}^{-1}$. Por otro lado, Gusakov, Kondratyeva \& Sinitsyn (2011), en un estudio sobre $\alpha$-amilasa alcalófila de la cepa GM8901 de Bacillus, por el método DNS encontraron que la actividad enzimática máxima fue de $0.75 \mathrm{U} \mathrm{ml}^{-1}$, después de la incubación de 24 horas. No obstante, Hasan, Wal, Hosna, Hakim \& Kalam (2017) obtuvieron del Bacillus spp. $3.50 \mathrm{U} \mathrm{ml}^{-1} \mathrm{de}$ actividad enzimática en 48 horas. Oyeleke, Auta \& Egwim (2010) reportaron para la amilasa de Bacillus megaterium $0.31-0.46 \mathrm{U} \mathrm{ml}^{-1} \mathrm{de}$ actividad enzimática amilolítica a $\mathrm{pH}$ alcalino.

\section{CONCLUSIONES}

Las a milas as de Geobacillus thermoparaffinivorans (CB-13) originan un diámetro de halo de hidrólisis de almidón de 10.6 $\mathrm{mm}$ con una producción de amilasas máxima de $0.197 \mathrm{mg} \mathrm{ml}^{-1}$, obtenida a las 48 horas y una actividad enzimática máxima de $0.505 \mathrm{U} \mathrm{ml}^{-1}$ a las 36 horas.

\section{AGRADECIMIENTO}

Al Proyecto de Investigación "Producción Biotecnológica de enzimas industriales a partir de microorganismos termófilos de los Géiseres de
Calientes, Candarave - Tacna (R.R. N ${ }^{\circ}$ 37142018-UN/JBG), por brindarnos las facilidades y el apoyo en el desarrollo de esta investigación.

\section{REFERENCIAS BIBLIOGRÁFICAS}

Aguirre, M. y Anduezal, F. (2018). Caracterización biotecnológica de bacterias aisladas de aguas termales del cantón Baños y sus posibles aplicaciones industriales (tesis de pregrado). Universidad Central del Ecuador, Ecuador.

Annamalai, N., Thavasi, R., Vijayalakshmi, S. \& Balasubramanian, T. (2011). Extraction, Purification and Characterization of Thermostable, Alkaline Tolerant $\alpha$-Amylase from Bacillus cereus. Indian Journal of Microbiology, 51(4), 424-429. doi: 10.1007/s12088-011-0160-Z

Bradford, M. (1976). A rapid and sensitive method for the quantitation of microgram quantities of protein utilizing the principle of protein-dye binding. Analytical Biochemistry, 72(1-2), 248-254. doi:10.1016/00032697(76) $90527-3$

Figen, E., Bilal, B., Seda, B. \& Tulin, A. (2006). Solid State Fermentation for the Production of $\alpha$ - Amylase from Penicillium chrysogenum Using Mixed Agricultural By-Products as Substrate. Biologia, Bratislava, 61(6), 657- 661. doi:10.2478/s11756-006$0137-2$

Gómez, S., Sarmiento, L. y Delgado, C. (2013). Caracterización de microorganismos celulolíticos y amilolíticos de residuos sólidos orgánicos dispuestos en la planta Ecosangil del municipio de San Gil, Santander. Revista Matices Tecnológicos, (5), 29-36. Recuperado de:http://publicaciones.unisangil.edu. co/index.php/revista-maticestecnologicos/article/view/206/193

Gomes, I., Gomes, J. \& Steiner, W. (2003). Highly thermostable amylase and pullulanase of the extreme thermophilic eubacterium Rhodothermus marinus: production and partial characterization. Bioresource Technology, 90(2), 207-214.

Guano, F. (2017). Evolución de las actividades celulasa, B-glucosidasa y amilasa durante el compostaje de lodos de depuradora y restos vegetales (tesis de maestría). Universidad de Almería, España. 
Gupta, R., Paresh, G., Mohapatra, H., Goswami, V. \& Chauhan, C. (2003). Microbial aamylases: a biotechnological perspective. Process Biochemistry, $38\left(\begin{array}{ll}1 & 1\end{array}\right), 1599-1616$. doi:10.1016/S0032-9592(03)00053-0

Gursahani, H. (2010). Studies on microbial thyermophilles of hot water springs of Maharashtra State (Ph.D. Thesis,) University, Aurangabad.

Gusakov, A., Kondratyeva, E. \& Sinitsyn, A. (2011). Comparison of Two Methods for Assaying Reducing Sugars in the Determination of Carbohydrase Activities. International Journal of A n a $1 \mathrm{y} \mathrm{t}$ i c a $1 \mathrm{Ch}$ e m i s t r y. doi:10.1155/2011/283658

Hasan, M., Wal, L.; Hosna, A.; Hakim, A. \& Kalam, A. (2017). Optimization of some fermentation conditions for the production of extracellular amylases by using Chryseobacterium and Bacillus isolates from organic kitchen wastes. Journal of Genetic Engineering and Biotechnology, $15(1)$ ) $59-68$. doi:10.1016/j.jgeb.2017.02.009

Konsoula, Z. \& Liakopoulou, M. (2007). Coproduction of alpha-amylase and betagalactosidase by Bacillus subtilis in complex organic substrates. Bioresource Technology,98 (1), 150157.

10.1016/j.biortech.2005.11.001

Kumar, S., Raut, S., Satpathy, S., Ranjan, P. \& Bandvopadhyay, B. ( 201014$)$. Characterizing Novel Thermophilic Amylase Producing Bacteria From Taptapani Hot Spring, Odisha, India. Jundishapur Journal of Microbiology, $7\left(\begin{array}{ll}1 & 2\end{array}\right)$, e 11800 . d o i : $10.5812 /$ jjm. 11800 .

Manoj, N. (2013). Thermostable alpha-amylase enzyme production from Bacillus laterosporus: Statisticaloptimization, purification and characterization. Biocatalysis and Agricultural Biotechnology,2(1), 38-44. doi: 10.1016/j.bcab.2012.10.005

Miller, G. (1959). Use of Dinitrosalicylic Acid Reagent For Determination of Reducing Sugar. Amal Chem., 31(3), 426-428.doi:10.1021/ac60147a030

Oyeleke, S., Auta, H. \& Egwim, E. (2010). Production and characterization of amylase produced by Bacillus megaterium isolated from a local yam peel dumpsite in Minna, Niger State. Journal of Microbiology and Antimicrobials, 2(7), 88-92. Recuperado de https://www.research gate.net/publication/228513933_Prod uction_and characterization_of amyl ase produced by Bacillus megateri um_isolated from_a local_yam peel dümpsite_in_Minna_Niger_State

Pandey, A., Nigam, P., Soccol, C., Soccol, V, Singh, D. \& Mohan, R. (2000). Advances in microbial amylases. Applied Biochemistry and Biotechnology, (31), 135-152. Recuperado de https://pdfs.semantic scholar.org/79ad/7f31 ee3d1900a706b 400bdca796afce35a11.pdf

Prakash, O. \& Jaiswal, N. (2009). An Ideal Representative of Thermostable Enzymes. Applied biochemistry and biotechnology, 160(8), 2401-2414. doi: $10.1007 / \mathrm{s} 12010-009-8735-4$

Robledo,T. (2018). Estudio de los procesos biológicos y de la estructura de las comunidades microbianas en el proceso de compostaje de lodos de depuradora de aguas residuales urbanas en sistemas de membrana semipermeable (tesis doctoral). Universidad de Granada. España.

Souza, C. \& Leal, M. (2000). Culture conditions for the production of thermostable amylase by Bacillus sp. Brazilian Journal of Microbiology, 31(4), 298302 . R e c u p e r a d o d e http://www.scielo.br/pdf/bjm/v3 1 n $4 / a$ $11 \mathrm{v} 3 \ln 4$

Stamford, T., Stamford, N., Coelho, L. \& Araujo, J. ( $\left.\begin{array}{llll}2 & 0 & 0 & 1\end{array}\right)$. Production and characterization of a thermostable alpha-amylase from Nocardiopsis sp. endophyte of yam bean. Bioresource Technology, 76(2), 137-141.

Unal, A. (2015). Production of a-amylase from some thermophilic aspergillus species and optimization of its culture medium and enzyme activity. Academic journals, 14(47) 317093183. doi: 10.5897/AJB2015.14924

Windish, W. \& Mhatre, N. (1965).. Advances in applied microbiology. Microbial amylases, ( 7 ), $273-304$. doi:10.1016/S0065-2164(08)70389-7 